\title{
ENVIRONMENTAL POLLUTION AND HEALTH PROBLEMS OF WORKERS IN TOBACCO INDUSTRIES
}

\author{
M. S. Elias* and N .K. Saha' ${ }^{1}$ \\ Department of Psychology, University of Rajshahi, Rajshahi 6205, Bangladesh
}

\begin{abstract}
The effect of environmental pollution on subjective and mental health of the workers in tobacco industries has been investigated. A total of 540 workers, 340 from tobacco (polluted) industries and the remaining 200 from non-tobacco industries, were selected using simple random sampling technique. Workers included in the sample were interviewed with three measuring instruments: (a) The Inventory of Subjective Health, (b) The General Health Questionnaire and (c) The Interview Schedule on Personal and Health Related Questionnaire. The results showed that the workers of tobacco industries suffered more from subjective health and mental health related problems than those of the non-tobacco industries. The older ( $\geq 20$ yrs) workers perceived relatively better subjective health than the younger $(<20 \mathrm{yrs})$ whereas latter perceived better mental health than the former. Male workers were found to have better subjective and mental health compared to the female workers, and the unmarried workers had better mental health than the married workers. Moreover, unhygienic home environment, malnutrition, lack of health care facilities, use of raw materials, anxiety, tension and job dissatisfaction were some of the health risk factors as perceived by majority respondents of tobacco industries than that of the non-tobacco industries.
\end{abstract}

Key words: Pollution, subjective health, mental health, tobacco industry

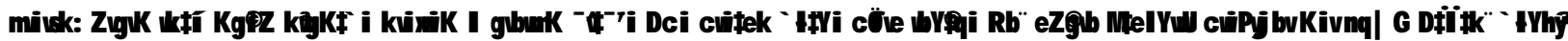

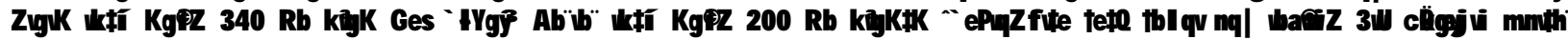

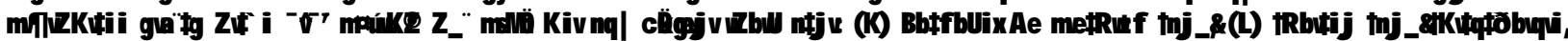

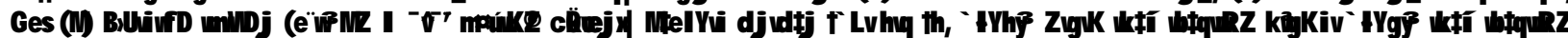

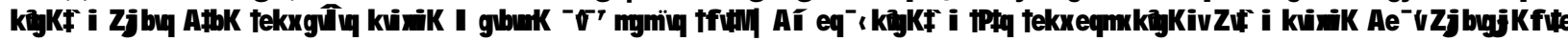

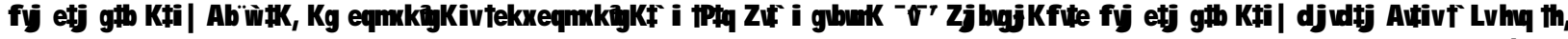
bu $x k$ 觔

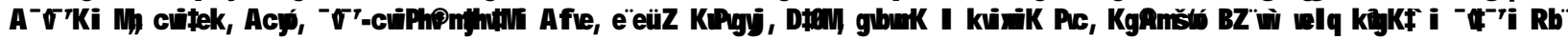

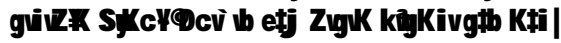

\section{Introduction}

Environmental pollution may affect human beings directly or through his physical objects, possessions or opportunities for recreation and appreciation of nature (Trivedi and Raj 1992). Atmospheric pollutants like dusts, fumes, and mists cause air pollution which adversely affects human health and creates annoyance to human eyes, irritation to nose and throat, and damage to human health through headache, allergies, nausea and similar effects (Trivedi and Raj 1992). The great majority of occupational poisonings result from breathing air containing toxic substances in the form of gases, vapours, mists, dusts or fumes and mixtures of two or more of these (Blake 1963). Studies of people exposed by occupational inhalation of inorganic toxic substances show greatly increased incidences of skin and internal turners (Lee and Frauineni 1969). Exposure to dust of grains, rice, cocoa, coconut fibres, tea, kapok, tobacco and wood is common in countries where these products are grown. There is evidence that such exposures may cause obstructive respiratory diseases and asthma both in children and adults (Cohen et al. 1972, David et al. 1972, Faith and Atkinson 1972,
Filley 1972, Selikoff 1972, French et al. 1973, Higgins and Ferris 1975).

Mental health is concerned with the adjustments individuals make to situations and the factors, which influence these adjustments (Argyris 1964, Herzberg 1968). This refers to behaviours, attitudes and feelings that represent an individual's level of personal effectiveness, success and satisfaction (Allport 1958, Jahoda 1958, Kornhauser 1965).

In a study U.S. Department of Health, Education, and Welfare (DoH 1967) found significant correlation between environmental pollution and physical or mental diseases such as mental disorders, nervous system diseases, and arthritis. Vaernes et al. (1988) examined a group of 127 workers for health complaints, subjective experience of their work environment, psychological defense strategies, and immunological factors, and found sleep disturbance and gastrointestinal problems as the main health complaints. The workers also complained about allergies, breathing difficulties, tension, anxiety and depression due to the adverse working environment. After a broad investigation of such symptoms as headache, general fatigue, anxiety, feelings of depression and

*Corresponding author (email: elias_psy@yahoo.com); ${ }^{1}$ Department of Psychology, Rajshahi Government College, Rajshahi 
bad temper, Rey (1977) considered these symptoms as an index of workers' ill health. The combination of industrial hazards may be more harmful to health than the sum of their individual effects (Rey 1977).

Adverse effects of environmental pollution on health of the workers were also observed by a number of researchers, who found that the exposure to bad working conditions, to chemical or physical noxious agents, may lead to specific occupational diseases and which, in turn, affect workers health and well being (Weintraub 1974, Quinn et al. 1974, Hennigan and Worthan 1975, O'Toole 1976, Jonson and Hansson 1977, WHO 1977, Beehr and Newman 1978, Evans and Jacobs 1981, Khaleque and Elias 1990, Khaleque et al. 1991, Khaleque and Elias 1995). Since a very few studies on environmental pollution and health problems of workers have so far been conducted in Bangladesh, the present study was aimed at investigating the effects of environmental pollution on subjective and mental health of the workers in tobacco industries.

\section{Materials and Methods}

Research setting: The present study was conducted on 14 tobacco (polluted) and 3 non-tobacco (non-polluted) industries, as categorized by the Directorate of Environment, Bangladesh. All these industrial plants were located in Rangpur District.

Sample size: Using simple random sampling technique, a total of 540 workers were selected from 2400 workers of tobacco and 750 workers of non-tobacco industries. Of these, 340 workers (210 males and 130 females) belonged to the tobacco industries, and the remaining 200 workers (120 males and 80 females) belonged to the non-tobacco industries.

Measuring instruments: Although a variety of health indices have been proposed so far, there is no ideal index of health. Based on a former proposition of Sigerist (1941), the definition of health indices recommended by the World Health Organization (WHO 1975, 1977) takes into account not only the absence of disease but also the individual's physical, mental and social well being. However, the following measuring instruments were used for collecting data for the present study.

(a) Inventory of subjective health: This scale was developed by Dirken (1967) to assess health complaints that consisted of 58 items, including 10 filler items, relating to different facets of subjective health. An adapted Bengali version of the inventory as proposed by Khaleque and Rahman (1987) was used in the present study.

(b) General health questionnaire (GHQ): This questionnaire was originally developed by Goldberg
(1972) which is a self-administered screening test for detecting minor psychiatric disorders. It consisted of 12 items with 4-point Likert-type scaling. Subsequent studies have provided evidence of the validity of GHQ. The mean corrected item-whole correlation for the GHQ was 0.84 and the alpha coefficient was 0.82 . Here we used an adapted Bengali version of the questionnaire (Khaleque and Siddique 1984).

(c) Personal and health related questionnaire: In addition to (a) and (b) scales mentioned above, an interview schedule developed by Khaleque (1988) was also used in the present study for obtaining some personal, demographic and health information of the subjects. The interview schedule consisted of a total of 36 questions.

\section{Results and Discussion}

Health problems and risk factors of workers: Results reveal that majority of the respondents of tobacco industries consider unhygienic work place and home environment, insufficient health care facilities and used raw materials as some of the important sources of their health problem as compared to the respondents of the non-tobacco industries (Table 1). Moreover, insufficient nutritious food, anxiety and tension, fatigue and job dissatisfaction were some of the health risk factors as perceived by the majority respondents of tobacco industries than those of their non-tobacco counterparts. The workers of the polluted industries suffered more from physical health problems (such as respiratory illness, coughing, pain in chest, loss of sleep, stomach upset and loss of appetite, feeling of dizziness and irritation) and psychological disturbances (such as anxiety, tension, depression, frustration, feeling of job dissatisfaction, feeling of drowsiness, and decrement of arousal) than those of the non-polluted industries. The results of the present study also clearly demonstrated significant differences between the workers of the polluted and non-polluted industries in terms of their subjective health and mental health complaints. It may be argued that the acute toxic effects from chemical pollutants occur with considerable frequency as a result of dermal and inhalation exposures in the course of work may have an adverse effect on the health of the workers. The workers who were exposed to air pollutants, chiefly sulfur dioxide, hydrogen sulfide and particulates, show an incidence of common respiratory diseases and the increased frequencies of acute respiratory illnesses. Since mental health of the workers is highly associated with the adjustments they make to situations and the factors which influence these adjustments, there is well-founded reason that the mental health of the workers will be adversely affected by the chronic toxic effects of the polluted working environment. 
Table 1. Workers' perception of health problems and risk factors in tobacco vs. non-tobacco industries

\begin{tabular}{|l|c|c|}
\hline \multicolumn{1}{|c|}{ Type of health problems and risk factors } & $\begin{array}{c}\text { Tobacco } \\
\text { industries }\end{array}$ & $\begin{array}{c}\text { Non-tobacco } \\
\text { industries }\end{array}$ \\
\hline The respondents who perceive their job factor (raw materials) as harmful to health. & $97.4 \%$ & $81.0 \%$ \\
\hline The respondents who perceive their work place environment as harmful to health. & $97.4 \%$ & $82.0 \%$ \\
\hline The respondents who perceive their home environment as harmful to health. & $88.8 \%$ & $18.0 \%$ \\
\hline The respondents who think that transport problem is a health risk factor. & $5 \%$ & $41.0 \%$ \\
\hline The respondents who think that insufficient nutritious food is a health risk factor. & $100 \%$ & $88.5 \%$ \\
\hline The respondents who think that anxiety and tension is a health risk factor. & $100 \%$ & $97.5 \%$ \\
\hline The respondents who think that job related fatigue is a health risk factor. & $100 \%$ & $83.0 \%$ \\
\hline The respondents who consider health care facilities insufficient. & $100 \%$ & $97.5 \%$ \\
\hline The respondents who think that job dissatisfaction is a potential health risk factor. & $100 \%$ & $83.5 \%$ \\
\hline
\end{tabular}

Subjective health complaints: Analysis of variance table showing the subjective health complaints of the workers of tobacco and non-tobacco industries in terms of their ages, gender and marital status is presented in Table 2. Results revealed that there exists a highly significant effect of pollution on workers' subjective health $\left(\mathrm{F}_{1,534}=922.328\right.$; $\mathrm{P}<0.001)$. The results also demonstrate that the effect of age $\left(\mathrm{F}_{1,534}=3.024 ; \mathrm{P}<0.05\right)$ was statistically significant but the interaction between pollution and age was not significant. Thus the results indicate that both pollution and age level of the workers have significant effect on their perceived subjective health. Like wise, the effects of pollution $\left(\mathrm{F}_{1,536}=1051.944 ; \mathrm{P}<.001\right)$, gender $\left(\mathrm{F}_{1,536}=\right.$ 46.554; $\mathrm{P}<0.001)$ and their interaction $\left(\mathrm{F}_{1,536}=35.247\right.$; $\mathrm{P}<0.001)$ on subjective health of the workers all were statistically significant. Unlike age and gender, however, the effects of marital status and its interaction with pollution on the subjective health of the workers had no significant effect.

Mental health complaints: The fact that workers of the tobacco industries suffer significantly more from psychological disturbances than those of the nontobacco industries is clearly demonstrated by the results shown in Table 3. Pollution $\left(\mathrm{F}_{1,534}=806.267 ; \mathrm{P}<0.001\right)$, age $\left(\mathrm{F}_{1,534}=4.727 ; \mathrm{P}<0.01\right)$ and their interaction $\left(\mathrm{F}_{1,534}\right.$ $=4.553 ; \mathrm{P}<0.05)$ all had statistically significant effects on the mental health of the workers. Moreover, the results also revealed that the effects of pollution $\left(\mathrm{F}_{1,536}=\right.$ 899.181; $\mathrm{P}<.001)$, gender $\left(\mathrm{F}_{1,536}=46.428 ; \mathrm{P}<0.001\right)$ and their interaction $\left(\mathrm{F}_{1,536}=33.808 ; \mathrm{P}<0.001\right)$ all were statistically significant, indicating that the mental health of the workers was adversely affected by the gender and work place pollution. Remarkably, the mental health of the workers was further adversely affected by both the pollution of work place and marital status $\left(\mathrm{F}_{1,536}=\right.$ 13.304; $\mathrm{P}<0.001)$ as well as the interaction $\left(\mathrm{F}_{1,536}=\right.$ 12.853; $\mathrm{P}<0.001$ ) between these two parameters.

A number of studies provide evidence in favour of the findings that the respiratory illness (Selikoff 1972, Cohen et al. 1972, Higgings and Ferris 1973, Freanch et al. 1973, Rey 1977) and cardiovascular diseases (David et al. 1972, Filley 1972, Jonson and Hensson 1977) are aggravated with the increased levels of pollutants. The findings also support the view that the health and well beings of the workers are directly related to the levels of pollution of their working environment (DoH 1967), Faith and Atkinson 1972, Khaleque et al. 1987, Khaleque and Elias1990, 1995). The present results showed that the age level had significant effects on both subjective and mental health of the industry workers. It was also found that the workers of all ages in nontobacco industries were enjoying relatively better subjective and mental health conditions than those of their counterpart tobacco industries. The older workers ( $\geq 30 \mathrm{yrs}$ ) perceived relatively better subjective health in comparison with the younger colleagues $(<30 \mathrm{yrs})$, suggesting that the older age-group might have developed some sort of body resistance because of longtime exposure to polluted environment. Continuous exposure to a toxic environment has been found to cause cumulative adverse effect on the health and wellbeings of the individuals (WHO 1977). Again, as expected, the younger workers $(<20 \mathrm{yrs})$ were enjoying better mental health compared to the older workers. It may be that most of younger workers were unmarried or recently married who had the minimum responsibilities for the family, rather they have had availed the scope to contribute to their parental families. This age-group was satisfied because they have been earning in their early life. Workers of the older age-group ( $>20 \mathrm{yrs})$ were not satisfied with their job because of their inability to meet up their raising family expenditure by their low income. Both the male and female workers of the non-polluted industries have been enjoying better subjective and mental health than the workers of the polluted industries. The male workers were found to have better subjective and mental health than their female counterparts. The causes of difference between the male and female workers' conditions may be explained in the way that the female workers have to work under a lot of pressure. Most of them got early married, had a number 
of children, lacked nutritious food, insufficient health care facilities and belonged to hand to mouth socioeconomic conditions. Most of them were divorced, separated or abandoned. As a result, they all had ill health and were suffering from many diseases. That is why they had to survive with poor subjective and mental health conditions than their male colleagues.

The present study also provides evidence that the workers' marital status had a significant effect on their mental health but not on their subjective health. It indicates that the unmarried workers were enjoying better mental health in comparison with the married workers. This is because the unmarried workers have relatively low family burden, and there is a scope of contributing to their parental families at an early age. Both the married and unmarried workers of the nonpolluted industries were enjoying better subjective as well as mental health conditions than the workers of the polluted industries. One thing worth mentioning here is that the scores of all the tobacco workers on different scales were found below average, which indicates the poor subjective and mental health conditions of these workers under study. In the light of all above findings, it could be concluded that appropriate preventive measures should be taken to protect the tobacco industries and their surrounding areas from pollution, so that good subjective as well as mental health conditions of the workers could be ensured.

Table 2. Two-way ANOVA for subjective health complaints of the workers of tobacco and non- tobacco industries in terms of their ages $(<20,20-29$ or $\geq 30 \mathrm{yrs})$, gender and marital status

\begin{tabular}{|l|l|l|l|l|l|}
\hline $\begin{array}{c}\text { Sources of } \\
\text { variations }\end{array}$ & \multicolumn{1}{|c|}{ SS } & Df & \multicolumn{1}{|c|}{ MS } & F-ratios & P-values \\
\hline Pollution (P) & 25876.799 & 1 & 25876.799 & 922.328 & $<0.001$ \\
\hline Age (A) & 169.695 & 2 & 84.847 & 3.024 & $<0.05$ \\
\hline $\mathrm{P} \times$ A & 45.721 & 2 & 22.861 & 0.815 & ns \\
\hline Error & 14981.889 & 534 & 28.056 & & \\
\hline Total & 325264.000 & 540 & & & \\
\hline \multicolumn{7}{|l|}{} \\
\hline Pollution (P) & 25876.799 & 1 & 25876.799 & 1051.944 & $<0.001$ \\
\hline Gender (G) & 1145.172 & 1 & 1145.172 & 46.554 & $<0.001$ \\
\hline P $\times$ G & 867.054 & 1 & 867.054 & 35.247 & $<0.001$ \\
\hline Error & 13185.079 & 536 & 24.599 & & \\
\hline Total & 325264.000 & 540 & & & \\
\hline \multicolumn{7}{|l|}{} \\
\hline Pollution (P) & 25876.799 & 1 & 25876.799 & 914.534 & 0.001 \\
\hline $\begin{array}{l}\text { Marital } \\
\text { status (M) }\end{array}$ & 30.386 & 1 & 30.386 & 1.074 & $\mathrm{~ns}$ \\
\hline P $\times$ M & 0.766 & 1 & 0.766 & 0.027 & ns \\
\hline Error & 15166.154 & 536 & 28.295 & & \\
\hline Total & 325264.000 & 540 & & & \\
\hline
\end{tabular}

$\mathrm{Ns}=$ not significant
Table 3. Two-way ANOVA for mental health complaints of the workers of tobacco and non- tobacco industries in terms of their ages $(<20,20-29$ or $\geq 30 \mathrm{yrs})$, gender and marital status

\begin{tabular}{|l|l|l|l|l|l|}
\hline $\begin{array}{l}\text { Sources of } \\
\text { variations }\end{array}$ & \multicolumn{1}{|c|}{ SS } & \multicolumn{1}{|c|}{ Df } & \multicolumn{1}{|c|}{ MS } & F-ratios & P-values \\
\hline Pollution (P) & 10828.735 & 1 & 10828.735 & 806.267 & $<0.001$ \\
\hline Age (A) & 126.975 & 2 & 63.488 & 4.727 & $<0.01$ \\
\hline $\mathrm{P} \times \mathrm{A}$ & 122.287 & 2 & 61.143 & 4.553 & $<0.05$ \\
\hline Error & 7171.996 & 534 & 13.431 & & \\
\hline Total & 204994.000 & 540 & & & \\
\hline \multicolumn{7}{|l|}{} \\
\hline Pollution (P) & 10828.735 & 1 & 10828.735 & 899.181 & $<0.001$ \\
\hline Gender (G) & 559.126 & 1 & 559.126 & 46.428 & $<0.001$ \\
\hline P $\times$ G & 407.143 & 1 & 407.143 & 33.808 & $<0.001$ \\
\hline Error & 6454.989 & 536 & 12.043 & & \\
\hline Total & 204994.000 & 540 & & & \\
\hline \multicolumn{7}{|l|}{} & & \\
\hline Pollution (P) & 10828.735 & 1 & 10828.735 & 820.270 & $<0.001$ \\
\hline $\begin{array}{l}\text { Marital } \\
\text { status }(\mathrm{M})\end{array}$ & 175.631 & 1 & 175.631 & 13.304 & $<0.001$ \\
\hline $\mathrm{P} \times \mathrm{M}$ & 169.680 & 1 & 169.680 & 12.853 & $<0.001$ \\
\hline Error & 7075.947 & 536 & 13.201 & & \\
\hline Total & 204994.000 & 540 & & & \\
\hline
\end{tabular}

\section{References}

Allport GW. 1958. Personality: Normal and abnormal. Sociol. Rev. 6: 167-180.

Argyris C. 1964. Integrating the Individual and the Organization. Harper, NY, USA.

Blake RP. 1963. Industrial Safety ( ${ }^{\text {rd }}$ edn.). Prentice-Hall Inc. Englewood, Clifts, NJ.

Beehr TA and Newman JE. 1978. Job stress, employee health, and organizational effectiveness: A facet analysis, model and literature review. Per. Psychol. 31: 665-699.

Cohen AA, Bromberg S and Buechley R W. 1972. Asthma and air pollution from a coal-fueled power plant. Amer. J. Pub. Health 62: 1181-1188.

David O, Clark J, and Voeller K.1972. Lead and hyperactivity. Lancet 2: 900.

Dirken J M. 1967. The measurement of stress in industrial situations. Groningen, Wolters : The Netherlands.

DoH (US Department of Health, Education and Welfare) 1967. Occupational Characteristics of Disabled Workers by Disabling Condition. Public Health Service Publ. No.1531. Government Printing Office, Washington, D. C.

Evans GW and Jacobs SV. 1981. Air pollution and human behavior. J. Social Issues 37: 95-125.

Faith WL and Atkinson AA. 1972. Air Pollution ( $2^{\text {nd }}$ edn.). John Wiley \& Sons, Inc. 
Filley GF 1972. The effects of chronic respiratory disease on the function of the lungs and heart. In: Environmental Factors in Respiratory Disease (Ed. D.H.K. Lee). Academic Press Inc., NY.

French RP, Rogers W and Cobb S. 1973. The effect of sulfur dioxide and suspended sulfates on acute respiratory disease. Archives of Environmental Health 27.

Goldberg D. 1972. The Detection of Psychiatric Illness by Questionnaire. Oxford University Press, London.

Hennigan JK and Wortham AW. 1975. Analysis of workday stress on industrial managers using heart rate as a criterion. Ergonomics 18: 675-685S.

Herzberg F. 1968. Work and the Nature of Man. Staples Press, London.

Higgins ITT and Ferris BG Jr. 1973. Epidemiology of sulphur oxides and particulates. In: Proceedings of the Conference on Health Effects of Air pollutant. Assembly of Life Sciences, National Academy of Sciences. National Research Council (prepared for the Committee on Public works, U.S. Senate), Washington, D.C.

Jahoda M. 1958. Current Concepts of Mental Health. Basic Books. NY.

Jonson A and Hansson I.1977. Prolonged exposure to a stress full stimulus (noise) as a cause of raised blood pressure in man. Lancet 1: 86-87.

Khaleque A. 1988. The Interview Schedule on Personal and Health Related Questionnaire. Unpub. PhD thesis, Department of Psychology, University of Dhaka, Bangladesh.

Khaleque A and Elias MS.1990. Effects of workplace pollution on health and well-being of workers. In: Human Factors in Organizational Design and Management-III (eds. Noro, K. And Brown, O), pp. 185-188, Elsevier Science Publisher, Amsterdam.

Khaleque A and Elias MS. 1995. Industrial pollution and quality of life of workers in Bangladesh. J. Human Ergology 24(1): 13-23.

Khaleque A and Rahman M A.1987. Perceived importance of job facets and overall job satisfaction of industrial workers. Human Relations 40(7): 401-416.

Khaleque A and Siddique AB. 1984. Job satisfaction and quality of life in shift work. Proceedings of the International Conference on Occupational Ergonomics. Toronto, Canada.
Khaleque A, Wadud N and Khanam M.1991. Environmental pollution and health hazards of industrial workers. In: Designing for Everyone (eds. Queinnec, Y. and Daniel OUF), pp. 957-959. Taylor and Francis Ltd., Paris.

Kornhauser AW. 1965. Mental Health of Industrial Workers: A Detroit Study. Wiley, NY.

Lee KM and Fraumeni JF. 1969. Arsenic and respiratory cancer in man: An occupational study. J. National Cancer Institute 42: 1045.

O' Tolle J. 1976. Work and the Quality of Life: Resource Papers for War in America. MIT Press. Cambridge, MA.

Quinn RP, Staines GL and McCullought MR. 1974. Job satisfaction: Is there trend? Washington, D. C.: US Department of Labor, Manpower Research Monograph. No.30.

Rey P, Baly M and Ramaciotti D. 1977. Symptoms respirators chroniques dans une population exposee professionnellement a different forms de pollution d i'air. Medicine et Hygiene 1228: 522-525.

Selikoff IL.1972. Occupational lung diseases. In: Environmental Factors in Respiratory Disease, Academic Press, Inc. NY.

Sigerist HE. 1941. Medicine and Human Welfare. Oxford University Press, New Haven, London.

Trivedi PR and Raj G. 1992. The environment and emerging development issues, Encyclopedia of Environmental Sciences, Akashdeep Publishing House, New Delhi, (Vol 1).

Vaernes RJ, Knardahi S, Romsing J, Aakvaag A, Tonder O, Walther B, and Ursin, H. 1988. Relations between environmental problems, psychology and health among shift-workers in the Norwegian process industry. Work and Stress 2(1): 7-15.

Waeintraub J. 1974. The relationship between job satisfaction and perceived states of health: A multivariate investigation. Unpub. PhD thesis, Bowling Green State University, 1973 (Dissertation Abstracts International 34, 41118).

WHO 1975. Technical Report Series. No. 574. Geneva, Switzerland.

WHO 1977. Expert Committee on Food Additives. WHO Technical Report Series. No. 601. Geneva, Switzerland. 